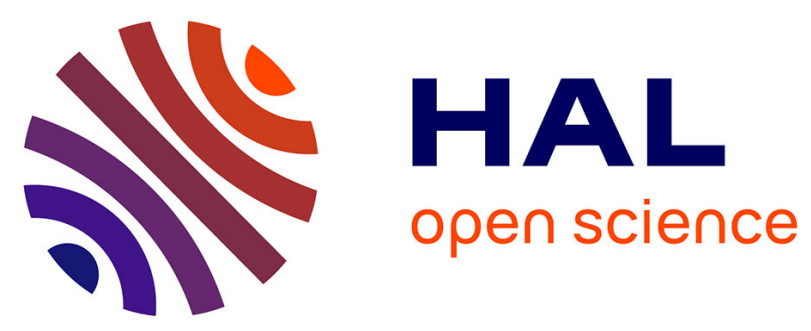

\title{
Advanced Cytoreduction as Surgical Standard of Care and Hyperthermic Intraperitoneal Chemotherapy as Promising Treatment in Epithelial Ovarian Cancer: Review of Literature Data
}

\author{
M. Deraco, D. Baratti, B. Laterza, M.R. Balestra, E. Mingrone, Macrì, S. \\ Virzì, F. Puccio, P.S. Ravenda, S. Kusamura
}

\section{To cite this version:}

M. Deraco, D. Baratti, B. Laterza, M.R. Balestra, E. Mingrone, et al.. Advanced Cytoreduction as Surgical Standard of Care and Hyperthermic Intraperitoneal Chemotherapy as Promising Treatment in Epithelial Ovarian Cancer: Review of Literature Data. EJSO - European Journal of Surgical Oncology, 2010, 37 (1), pp.4. 10.1016/j.ejso.2010.11.004 · hal-00651629

\author{
HAL Id: hal-00651629 \\ https://hal.science/hal-00651629
}

Submitted on 14 Dec 2011

HAL is a multi-disciplinary open access archive for the deposit and dissemination of scientific research documents, whether they are published or not. The documents may come from teaching and research institutions in France or abroad, or from public or private research centers.
L'archive ouverte pluridisciplinaire $\mathbf{H A L}$, est destinée au dépôt et à la diffusion de documents scientifiques de niveau recherche, publiés ou non, émanant des établissements d'enseignement et de recherche français ou étrangers, des laboratoires publics ou privés. 


\section{Accepted Manuscript}

Title: Advanced Cytoreduction as Surgical Standard of Care and Hyperthermic Intraperitoneal Chemotherapy as Promising Treatment in Epithelial Ovarian Cancer: Review of Literature Data

Authors: M. Deraco, MD D. Baratti, MD B. Laterza, MD M.R. Balestra, MD E. Mingrone, MD Macrì, MD S. Virzì, MD F. Puccio, MD P.S. Ravenda, MD S. Kusamura, MD PhD

PII: S0748-7983(10)00577-9

DOI: 10.1016/j.ejso.2010.11.004

Reference: $\quad$ YEJSO 3075

To appear in: European Journal of Surgical Oncology

Received Date: 12 July 2010

Revised Date: 26 October 2010

Accepted Date: 1 November 2010

Please cite this article as: Deraco M, Baratti D, Laterza B, Balestra MR, Mingrone E, Macrì, Virzì S, Puccio F, Ravenda PS, Kusamura S. Advanced Cytoreduction as Surgical Standard of Care and Hyperthermic Intraperitoneal Chemotherapy as Promising Treatment in Epithelial Ovarian Cancer: Review of Literature Data, European Journal of Surgical Oncology (2010), doi: 10.1016/ j.ejso.2010.11.004

This is a PDF file of an unedited manuscript that has been accepted for publication. As a service to our customers we are providing this early version of the manuscript. The manuscript will undergo copyediting, typesetting, and review of the resulting proof before it is published in its final form. Please note that during the production process errors may be discovered which could affect the content, and all legal disclaimers that apply to the journal pertain. 
Advanced Cytoreduction as Surgical Standard of Care and Hyperthermic Intraperitoneal Chemotherapy as Promising Treatment in Epithelial Ovarian Cancer: Review of Literature Data

Deraco $M M^{1}$, Baratti $D M^{1}$, Laterza $B M^{1}$, Balestra $M R D^{1}$, Mingrone $E M^{2}$, Macrì $\mathrm{MD}^{3}$, Virzì S MD ${ }^{4}$ Puccio $F \mathrm{MD}^{5}$, Ravenda $\mathrm{PS} \mathrm{MD}^{6}$ and Kusamura S MD PhD ${ }^{1}$.

${ }^{1}$ Department of Surgery, Peritoneal Surface Malignancies Branch, National Cancer Institute, Milan; ${ }^{2}$ Department of General Surgery and Emergency University of Perugia; ${ }^{3}$ Department of General Surgery University of Messina; ${ }^{4}$ Department of General Surgery Bentivoglio-Bologna; ${ }^{5}$ Department of General Surgery Manerbio; ${ }^{6}$ Department of Medical Oncology University of Pavia: Italy

Correspondence address: Marcello Deraco MD. Responsible for Peritoneal Surface Malignancies, Istituto Nazionale Tumori Milano. Via Venezian n.1 20133 Milano, Italy. Phone number: +39.02.23902362; Fax number: +39.02.23902404; E-mail: marcello.deraco@istitutotumori.mi.it

Key-words: Cytoreductive Surgery, Peritonectomy; Hyperthermic Intraperitoneal Chemotherapy; Epithelial Ovarian Cancer, Peritoneal Carcinomatosis. 
Abstract: Favorable oncological outcomes have been reported in several trials with the introduction of Cytoreductive Surgery (CRS) and Hyperthermic Intraperitoneal Chemotherapy (HIPEC) in the treatment of Advanced Epithelial Ovarian Cancer (EOC). However most of the studies testing the combined approach are observational and has been conducted in inhomogeneous series so that the evidence supporting the performance of this combined treatment is still poor. Median Overall and Disease Free Survivals of up to 64 months and 57 months, respectively have been reported. Although a rate of morbidity of up to $40 \%$ has been observed in some series the CRS+HIPEC continues to gain an increased popularity. Several prospective randomized trials are ongoing using the procedure in various time points of the disease.

In this review several issues such as the impact of cytoreduction and residual disease (RD) on outcomes as well as the role of HIPEC will be updated from the literature evidence. Some controversial points HIPEC related will also be discussed.

Recent experiences regarding the introduction of a more aggressive surgical approach to upper abdomen to resect peritoneal carcinomatosis (PC) allowed increased rates of optimal cytoreduction and has demonstrated an apparent better outcome. This evidence associated with the positive results phase III trial testing normothermic intraperitoneal as first line chemotherapy is guiding some investigators to propose the CRS+HIPEC in the primary setting. Several prospective phase II and III trials have recently been launched to validate the role of the combined treatment in various time points of disease natural evolution. 


\section{Introduction}

Epithelial ovarian cancer (EOC) is one of the most common gynecologic malignancies and the fifth most frequent cause of cancer death in women. $\left.{ }^{1}\right]$ Most patients have widespread disease at presentation. $\left[^{2}\right]$ The conventional clinical approach for advanced EOC is based on CRS followed by adjuvant chemotherapy. Clinical studies have shown that cisplatin/taxol-based first-line chemotherapy achieves the highest response rates, with a high proportion of complete responses. $\left[{ }^{3},{ }^{4}\right]$ However, about 2 thirds of the patients relapse and ultimately die of chemoresitant disease.

\section{The role of Cytoreductive Surgery and Residual Disease (RD)}

A prominent meta-analysis supporting the importance of CRS in the treatment of EOC was published by Bristow et al. $\left[^{5}\right]$ They evaluated retrospectively the relative effect of percent maximal CRS and other prognostic variables on survival among 81 cohorts of patients including 6,885 with stage III/IV EOC, treated with cisplatin based chemotherapy. Maximal cytoreduction was concluded to be one of the most powerful determinants of survival.

Several factors concur for the accomplishment of an optimal cytoreduction: accurate preoperative identification of resectable cases, experience of the surgical team, favorable clinical condition of the patient, biological aggressiveness of the disease, the surgeon and patient's willingness to challenge the inherent increased morbidity of an extended operation. However, the essence of the problem is not operational. Although universally accepted as standard of care, the term CRS has been subject of a myriad of interpretations resulting in different concepts of optimal RD and advisable limits of radicality.

A recent retrospective review of 360 patients stage IV EOC who underwent primary surgery followed by 6 cycles of IV platinum/paclitaxel has provided important element to clear the issue. Median OS for microscopic, 0.1 to $5.0 \mathrm{~cm}$, and $>5.0 \mathrm{~cm}$ RD was 64,30 , and 19 months, respectively. The authors concluded that ultraradical surgeries might be targeted for selected patients in whom microscopic RD is achievable. $\left.{ }^{6}\right]$

A survey of the Society of Gynecologic Oncologists (SGO) revealed $12.0 \%$ to think of removing all visible disease as "optimal", $13.7 \%$ use a $0.5 \mathrm{~cm}$ threshold, $60.8 \%$ a $1 \mathrm{~cm}$ threshold, $3.6 \%$ a $1.5 \mathrm{~cm}$ threshold, $8.7 \%$ a $2.0 \mathrm{~cm}$ threshold and $1.3 \%$ use other criteria such as the total estimated weight and/or volume of RD. [ [ ] 
The large spectrum encompassed by the different definitions of optimal cytoreduction could be resumed in 2 school of thoughts. The first one takes advantage of the high initial chemosensibility of the disease and tends to differ radical operations with multivisceral resections whenever it could be necessary to attain minimal RD in order to avoid presumed morbidity. Supporters of such a police state that evidence of survival benefit coming from ultraradical procedure is not sufficient and attribute a major prognostic significance to chemotherapy.

The second one - which is based on the assumption that the RD is the most important prognostic factor - is surgically oriented and tend to push the limits the radicality as far as technically it is possible to be done. Extensive procedures including multi-organ resections, in order to achieve highest rate of complete cytoreduction, is systematically pursued, despite potential increase in side effect rates. Representatives of the second school of thought are the minority in the EOC management scenario. However, interesting data have been published thus far that substantiate a surgically aggressive police.

Eisenkop et al. reported on 213 patients with Stage IIIC EOC undergoing complete cytoreduction before initiation of systemic chemotherapy. The median and estimated 5year survival were 75.8 months and $54 \%$, respectively. Survival was influenced by the requirement of diaphragm stripping and the extent of mesenteric and serosal implants that required removal. $\left[{ }^{8}\right]$

Investigators from Memorial Sloan Kettering Cancer Center have introduced a more radical surgical approach including advanced procedures - such as diaphragm stripping and/or full thickness resection, splenectomy, hepatectomy, porta hepatis dissection, bowel resections - to approach peritoneal carcinomatosis (PC), especially in the upper abdomen. A recent report on 398 patients assigned to 2 non-randomized groups, but well balanced with respect the main covariates, allowed the conclusion that such aggressive surgical policy resulted in increased optimal cytoreduction rates and significantly improved oncological outcome. $\left[^{9}\right]$

However, supporters of the first school of thought argue that complete cytoreduction in most cases is attained thanks to relatively small tumour burdens and presumed diminished biological aggressiveness of neoplasms rather than to maximal surgical effort. $\left[{ }^{10}\right]$

Eisenkop et al. observed that the need to remove a large number of peritoneal implants correlates with biological aggressiveness and diminished survival, but not 
significantly enough to preclude long-term survival or justify abbreviation of the operative effort.[7] On the other hand, an exploratory analysis in the context of a large randomized trial (SCOTROC) has shown a significant benefit in PFS correlated with optimal surgery in stage IIIC to IV disease, that is limited to patients with less advanced disease. $\left[{ }^{11}\right]$

The question of relative influence of tumor biology and actual impact of complete cytoreduction on outcome has been further elucidated by a provocative study evaluating tumor-infiltrating lymphocytes and/or tumor mitotic activity on 134 patients with stage III/IV serous or poorly differentiated ovarian adenocarcinoma undergoing primary CRS. $\left.{ }^{12}\right]$ Patients whose tumors exhibited low Ki67 expression and high intraepithelial CD8(+) frequency had a better outcome with a 5 -year survival rate of $73.3 \%$. The finding worthy of note was that patients with aggressive biology - low frequency of intraepithelial CD8(+) T cells or high Ki67 expression - were more likely to benefit from aggressive CRS. On the other hand, survival was similar for patients with brisk CD8(+) T cells or low Ki67 who had optimal or suboptimal cytoreduction. The study represents the first biological evidence that optimal cytoreduction is not a direct consequence of a favorable biological behavior, and that aggressive surgical approach is justified in poor prognostic subsets.

As for other Peritoneal Surface Malignancies (PSM), the advent of Peritonectomy Procedures is one of the most important contribution for the standardization of CRS. $\left.{ }^{13}\right]$ The adaptation of the original technique to the different diseases continues to be a challenge for the surgeons treating patients with PSM. The original systematic codification and further modifications, $\left[{ }^{14}\right]$ allow the best intraoperative surgical strategy by the following peritonectomy and multivisceral resections procedures:

- Upper Right Peritonectomy: right diaphragmatic peritonectomy with Glisson's capsule dissection; lesser omentectomy, stripping of the omental bursa \pm cholecystectomy \pm gastric antrectomy or total gastrectomy

- Upper Left Peritonectomy: left diaphragmatic and parietal peritonectomy with splenectomy and greater omentectomy;

- Pelvic Peritonectomy: pelvic parietal peritonectomy \pm sigmoidectomy \pm hysterectomy and salpingo-oophorectomy;

- Right Parietal Peritonectomy \pm right/total colectomy;

- Mesenteric Peritonectomy implants on visceral surfaces could be alternatively removed by electrosurgical local dissection.

\section{Hyperthermic Intraperitoneal Chemotherapy}


The evolution of management of advanced EOC in the last decade has been characterized by the validation of intraperitoneal chemotherapy (IP). The GOG-172 phase III trial favored the intravenous (IV) plus IP chemotherapy over IV chemotherapy in primary stage III EOC. $\left.{ }^{15}\right]$ Successively, a Cochrane meta-analysis of all randomized IP versus IV trials showed a hazard ratio of 0.79 for disease-free survival (DFS) and 0.79 for OS, favoring the IP arms. $\left[{ }^{16}, 16^{17}\right]$

Other prominent advance in the EOC management has been the advent of hyperthermic intraperioneal chemotherapy (HIPEC). It has been employment in the treatment of PSM following CRS and positive outcome results have been reported for PC from appendiceal cancer, $\left[{ }^{18}\right]$ colorectal cancer, $\left[{ }^{19}\right]$ and peritoneal mesothelioma. $\left[{ }^{20}\right]$

The theoretical rationale for HIPEC for the treatment of advanced EOC is to combine the demonstrated pharmacological activity of IP chemotherapy in this disease with the advantage of intraoperative hyperthermia, that exerts an enhancement of cytotoxicity, enabling a microscopic cytoreduction, following a macroscopic cytoreduction obtained with CRS.

Recently Chua TC. et al. have published a systematic review of 19 observational studies that reported the efficacy of CRS+HIPEC for advanced EOC. $\left[{ }^{21}\right]$ The HIPEC protocol varied in each institution. The most commonly used chemotherapy was Cisplatin. Eleven out of 19 studies employed the CRS+HIPEC as primary treatment for a proportion of their patients and 11/19 studies employed it as salvage therapy. The overall rate of severe perioperative morbidity ranged from 0 to $40 \%$ and mortality rate from 0 to $10 \%$. The median OS following treatment ranged from 22 to 64 months with a median DFS ranging from 10 to 57 months. In patients with optimal cytoreduction, a 5-year OS ranged from $12 \%$ to $66 \%$.

It is hard to ascertain in which extent the apparent survival advantage reported by these uncontrolled clinical studies resulted from selection bias. Moreover, the investigations involved heterogeneous patient population, at different time points of disease evolution, usually heavily pre-treated, and therefore, with different tumor chemoresistances.

\section{Controversial Points}


The growing body of literature observed in recent years testing the CRS+HIPEC in EOC - a direct consequence of its increasing popularity in the scientific community - has been responsible for the emergence of various controversies.

\section{Timing of CRS and HIPEC}

A major controversial issue is the time point of the natural history of EOC for the performance CRS+HIPEC. The recent data recommending maximal surgical effort [5] and IP [16] chemotherapy in the primary setting represents a indirect evidence that CRS+HIPEC could be tested as upfront treatment in the context of a phase III trial.

The CRS+HIPEC could also be tested after neoadjuvant chemotherapy (NACT) in an attempt to increase the likelihood of optimal cytoreduction. A recent large randomized study has compared the primary cytoreduction with NACT. $\left.{ }^{22}\right]$ The investigators reported similar results in terms of PFS and OS between the study arms and lower morbidity associated with NACT. These results have been corroborated with a recent meta analysis. $\left[{ }^{23}\right]$ No studies have been conducted thus far testing the effects of CRS+HIPEC following NACT.

In order to further minimize the morbidity, the CRS+HIPEC has been recently tested as consolidation treatment by some investigators. $\left[{ }^{24},{ }^{25}\right]$ The consolidation setting represents an attracting option as the tumor burden after completion of adjuvant systemic chemotherapy is expected to be low and as well as the inherent the possible complication(s) related to cytoreduction. Kim et al. reported on 18 stage Ic-IIlc EOC patients with a negative second-look who were submitted to HIPEC using paclitaxel. The 8 year OS rate resulted to be of $84 \%$.[24] In contrast, Pomel et al. have not found the same favorable results. They employed oxaliplatin for HIPEC and verified the emergence of unacceptable rate of post operative bleeding that constrained the premature closure of the trial.[25]

The last time point in which CRS+HIPEC has been tested is as second-line treatment. The influence of secondary CRS (without HIPEC) on survival outcomes has been addressed in a substantial number of publications and has been recently systematically reviewed. $\left[{ }^{26}\right]$ However these were non-controlled studies of secondary CRS investigating the impact on survival. A consistent survival data comparing secondary CRS 
with chemotherapy is expected to be provided by the ongoing randomized trial AGOOVAR OP4.[ $\left[{ }^{27}\right]$

Indirect evidence could also be extracted from the recently published exploratory analysis of the DESKTOP I trial that shed new insights not only on the value of a aggressive surgical approach in relapsing EOC, but also on the prognostic implications of PC. $\left[{ }^{28}\right]$ Two hundred fifty patients with recurrent EOC (50\% with PC) undergoing secondary cytoreduction were included in the analysis. The authors concluded that although the PC represented a negative predictor of complete resection it had no effect on prognosis if complete resection could be achieved.

Two subsets of patients must be clearly distinguished in the circumstance of a second-line treatment: platinum resistant and platinum sensitive ones. Experimental data sustains that a major synergism between cytotoxicity and the heat is achievable in cisplatin resistant cell lines with respect to platin sensitive ones. $\left[{ }^{29}\right]$ Based on this favorable in vitro evidence investigators from National Cancer Institute of Milan launched a phase III trial testing the CRS+HIPEC in platinum resistant EOC. The few patients that were recruited unfortunately presented high rate of morbidity and the trial was prematurely closed due to poor patient accrual.[Dr. Raspagliesi, NCI Milan, ${ }^{30}$ ]

Platin sensitive relapse has been deemed as the best clinical circumstance to test the combined treatment. $\left[{ }^{31}\right]$ However one could argue raising the hypothesis that the favorable oncological results presented by such studies would be achievable in any case irrespective of treatment (secondary cytoreduction +/- HIPEC vs systemic platin based chemotherapy) due to the favorable biological profile of the tumor.

According to the consensus statement (Milan 2006), the procedure could be employed in all time points (primary treatment, interval debulking, secondary cytoreduction, salvage treatment) with the exception of platinum resistant relapsing disease. $\left[{ }^{32}\right]$ The studies published since then do not allow further conclusion other than that established by the 2006 consensus statement.

\section{Time To Chemotherapy}

Clinicians often question whether a long postoperative time after patients undergo CRS+HIPEC could affect the Time To Chemotherapy (TTC) with a delayed start of adjuvant chemotherapy and consequently a reduced benefit of the extensive procedure. 
Aletti evaluated retrospectively data from 218 patients with stage IIIC/IV EOC. Mean TTC interval was 26 days (range, 7-79 days). TTC was not a predictor of OS allowing the conclusions that TTC interval should not be used to justify using a surgically more conservative approach for advanced EOC. $\left[{ }^{33}\right]$

\section{Staging System}

Another controversy regards the need for a new staging system (SS). It is expected that the surgical paradigm in the treatment of EOC is going to change to a more aggressive and radical operative approach in the near future. This means that the actual FIGO staging would become insufficient to help defining therapeutic strategies and new prognostic subsets. Recently Chéreau et al. has compared the International Federation Gynecology and Obstetrics (FIGO), Peritoneal Cancer Index (PCI), Eisenkop, Aletti, Fagotti, and Fagotti-modified scores regarding the accuracy to predict resectable disease, postoperative complications and oncological outcomes. In predicting resectability, Fagottimodified and $\mathrm{PCl}$ outperformed other scores. There was a strong association between the occurrence of postoperative complications and Aletti, $\mathrm{PCl}$, and Eisenkop scores. A significant differences among FIGO, PCl, Eisenkop, Fagotti-modified, and Aletti scores were observed concerning their correlation with PFS $(P<.05) \cdot\left[{ }^{34}\right]$

\section{Drugs}

Various drug combinations for EOC have been tested by experimental and phase I/II studies on HIPEC. Several parameters should guide the choice of the drug: pharmacokinetic profile, tumour chemosensibility and toxicity. Ideally the drug must be water-soluble and of high molecular weight in order to guarantee a low peritoneal clearance. This, combined with a high systemic clearance, results in pharmacological advantage expressed by the ratio AUCperitoneal/AUCplasma. The penetration ability of drug in the tumour is a function of passive diffusion (related to the AUCpe/AUCpl ratio), removal from by the capillary blood flow, temperature modulation. Finally, the influence of temperature in the cytotoxicity should also be of concern. The optimal choice of the drugs for HIPEC represents an another unclear topic in EOC treatment and is still impossible to be done on the basis of the literature data. Agents that have already been employed are Cisplatin,[35] Doxorubicin, [36] Caelyx,[37] Mitomycin C,[38] Mitoxantrone,[39] Carboplatin,[40] Oxaliplatin,[31] Gemcitabine [41] and Paclitaxel.[42] 


\section{Conclusion}

CRS represents one of the most powerful determinants of outcome and the strongest clinician-driven predictor of survival in patients with stage IIIC/IV EOC according to literature evidence. The resection of all visible implants should be considered the standard of the surgical approach. Peritonectomy Procedures, as a result of a change in surgical paradigm, could dramatically improve outcomes and should be advisably considered in EOC treatment.

The current tendency of recognizing the importance of maximal surgical effort in the management of EOC confirms the need to revise the actual staging criteria (FIGO). A new staging system should be able to guide the surgeon not only to identify the subsets characterized by different prognosis, but also provide information about resectability and potential post operative morbidity.

The appropriate management of advanced EOC patients requires the presence of a multidisciplinary team including surgeons specialized in CRS. A well structured and long lasting training program is necessary to allow gynaecologists and surgeons to overcome the steep learning curve of CRS using peritonectomy procedures. The performance of at least 130 procedures is necessary to consider the physician an expert in cytoreduction using the Sugarbaker technique. $\left.{ }^{43}\right]$ At this point national committees are advisable to be constituted to carefully evaluate if centres proposing to set up a peritoneal surface malignancy program meet all the requirements in terms of technical and human resources to perform the combined procedure safely and with optimal expertise.

Considering the potential advantages of HIPEC associated to CRS (Table 1), trials testing its efficacy should be encouraged in all time points of natural history of the disease, especially in up-front and platinum-sensitive recurrent disease. In this sense 3 randomized controlled trials are ongoing. The first proposes to test the efficacy of secondary cytoreduction with or without HIPEC and has been conducted by the Netherlands Cancer Institute. $\left.{ }^{44}\right]$ The second trial proposes to test the procedure in primary and secondary setting and has been conducted by St George Hospital, in Sydney. $\left[{ }^{45}\right]$ The third is a multicentric randomized trial proposed by a French group (CHIPOR) and aims to test the HIPEC for relapsing disease. $\left[{ }^{46}\right]$

\section{Conflict of interests}


The authors do not have any conflict of interest to disclose. 
Table 1: Literature results of patients with peritoneal carcinomatosis from EOC treated with CRS+HIPEC : most relevant experiences

\begin{tabular}{|c|c|c|c|c|c|c|c|}
\hline A Author (year) & $\begin{array}{c}\text { Patients } \\
\#\end{array}$ & $\begin{array}{l}\text { DFS (Med } \\
\text { mos) }\end{array}$ & $\begin{array}{l}\text { OS (Median } \\
\text { mos) }\end{array}$ & $\begin{array}{c}\text { OS of Complete CRS } \\
\text { (Med mos) }\end{array}$ & 3-year OS (\%) & 5-year OS (\%) & References \\
\hline $\begin{array}{l}\text { Bereder et al. } \\
\quad(2009)\end{array}$ & 246 & 13 & 49 & 56 & 60 & 35 & 47 \\
\hline $\begin{array}{l}\text { Pavlov et al. } \\
\quad(2009)\end{array}$ & 56 & 26 & 38 & NR & NR & NR & 48 \\
\hline $\begin{array}{l}\text { Fagotti et al. } \\
\text { (2009) }\end{array}$ & 25 & 10 & NR & NR & NR & NR & 31 \\
\hline $\begin{array}{c}\text { Guardiola et al. } \\
(2009)\end{array}$ & 47 & 14 & NR & NR & $63 a$ & NR & 49 \\
\hline $\begin{array}{c}\text { Di Giorgio et al. } \\
\text { (2008) }\end{array}$ & 47 & 20 & 24 & 26 & NR & 17 & 50 \\
\hline $\begin{array}{l}\text { Bae et al. } \\
\text { (2007) }\end{array}$ & 67 & NR & NR & NR & NR & 54 & 51 \\
\hline $\begin{array}{l}\text { Cotte et al. } \\
(2007)\end{array}$ & 81 & 19 & 28 & 55 & NR & 66 & 52 \\
\hline $\begin{array}{l}\text { Rufian et al. } \\
\quad(2006)\end{array}$ & 33 & NR & 48 & 66 & 46 & NR & 53 \\
\hline $\begin{array}{l}\text { Raspagliesi et } \\
\text { al. (2006) }\end{array}$ & 40 & 11 & 32 & NR & NR & 37 & 54 \\
\hline $\begin{array}{l}\text { Ryu et al. } \\
\text { (2004) }\end{array}$ & 57 & 26 & NR & 41 & NR & 15 & 55 \\
\hline
\end{tabular}

OS: Overall Survival; DFS: Disease Free Survival; Med: Median; mos: Months; 


\section{REFERENCES}

1 Yancik R: EOC. Age contrasts in incidence, histology, disease stage at diagnosis, and mortality. Cancer 1993;(71 2 Suppl):517-23.

${ }^{2}$ Hogg R, Friedlander M: Biology of epithelial EOC: implications for screening women at high genetic risk. J Clin Oncol 2004;22:1315-27.

${ }^{3}$ McGuire WP, Hoskin WJ, Brady MF, et al. Cyclophosphamide and Cisplatin compared with Paclitaxel and cisplatin in Patients with Stage III and IV EOC. N Engl. J Med. 1996; 334:1-6.

${ }^{4}$ Ozols RF, Young RC. EOC. Curr. Probl. Cancer, 1988;11: 57-122.

${ }^{5}$ Bristow RE, Tomacruz RS, Armstrong DK, Trimble EL, Montz FJ. Survival effect of maximal cytoreductive surgery for advanced ovarian carcinoma during the platinum era: a meta-analysis. J Clin Oncol. 2002;20:1248-59.

${ }^{6}$ Winter WE 3rd, Maxwell GL, Tian C, et al. Gynecologic Oncology Group. Tumor residual after surgical cytoreduction in prediction of clinical outcome in stage IV epithelial EOC: a Gynecologic Oncology Group Study. J Clin Oncol. 2008;26:83-9.

7 Eisenkop SM and Spirtos NM. What are the current surgical objectives, strategies, and technical capabilities of gynecologic oncologists treating advanced epithelial EOC? Gynecol. Oncol. 2001; 82;489-97.

${ }^{8}$ Eisenkop SM, Spirtos NM. Procedures required to accomplish complete cytoreduction of EOC: is there a correlation with "biological aggressiveness" and survival? Gynecol Oncol. 2001;82:435-41.

${ }^{9}$ Chi DS, Eisenhauer EL, Zivanovic O, et al. Improved progression-free and overall survival in advanced EOC as a result of a change in surgical paradigm. Gynecol Oncol. 2009;114:26-31

${ }^{10}$ Pfisterer J, Weber B, Reuss A, et al; AGO-OVAR; GINECO. Randomized phase III trial of topotecan following carboplatin and paclitaxel in first-line treatment of advanced EOC: a gynecologic cancer intergroup trial of the AGO-OVAR and GINECO. J Natl Cancer Inst. 2006;98:1036-45.

${ }^{11}$ Crawford SC, Vasey PA, Paul J, Hay A, Davis JA, Kaye SB. Does aggressive surgery only benefit patients with less advanced EOC? Results from an international comparison 
within the SCOTROC-1 Trial. J Clin Oncol. 2005;23:8802-11. Erratum in: J Clin Oncol. $2006 ; 24: 1224$.

12 Adams SF, Levine DA, Cadungog MG, et al. Intraepithelial T cells and tumor proliferation: impact on the benefit from surgical cytoreduction in advanced serous EOC. Cancer. 2009;115:2891-902.

${ }^{13}$ Sugarbaker Ph: Peritonectomy Procedures. Ann Surg 1995;221:29-42.

${ }^{14}$ Deraco M, Baratti D, Kusamura S, Laterza B and Balestra MR. Surgical technique of parietal and visceral peritonectomy for peritoneal surface malignancies. J Surg Oncol. 2009;100:321-8.

${ }^{15}$ Armstrong DK, Bundy B, Wenzel L, Huang HQ, Baergen R, Lele S et al. Intraperitoneal cisplatin and paclitaxel in EOC. N Engl J Med 2006;354:34-43.

16 Jaaback K, Johnson $\mathrm{N}$ : Intraperitoneal chemotherapy for the initial management of primary epithelial EOC. Cochrane Database Syst Rev. 2006;1:CD005340.

17 Rowan K. Intraperitoneal therapy for EOC: why has it not become standard? J Natl Cancer Inst. 2009;101:775-7.

18 Yan TD, Black D, Savady R, Sugarbaker PH. A systematic review on the efficacy of cytoreductive surgery and perioperative intraperitoneal chemotherapy for pseudomyxoma peritonei. Ann Surg Oncol 2007a;14:484-92.

19 Yan TD, Black D, Savady R, Sugarbaker PH. Systematic review on the efficacy of cytoreductive surgery combined with perioperative intraperitoneal chemotherapy for peritoneal carcinomatosis from colorectal carcinoma. J Clin Oncol 2006;24:4011-9.

20 Yan TD, Deraco M, Baratti D, et al. Cytoreductive surgery and hyperthermic intraperitoneal chemotherapy for malignant peritoneal mesothelioma: multi-institutional experience.J Clin Oncol. 2009; 27:6237-42.

21 Chua TC, Robertson G, Liauw W, et al. Intraoperative hyperthermic intraperitoneal chemotherapy after cytoreductive surgery in EOC peritoneal carcinomatosis: systematic review of current results. J Cancer Res Clin Oncol. 2009;135:1637-45.

22 Vergote CG, Trope F, Amant GB, et al. EORTC-GCG/NCIC-CTG randomized trial comparing primary debulking surgery with neoadjuvant chemotherapy in stage IIIC-IV ovarian, fallopian tube and peritoneal cancer. Plenary presentation at the 12 th Biennial 
meeting International Gynecologic Cancer Society IGCS, Bangkok, Thailand October 2528, 2008 (abs.) 2008.

${ }^{23}$ Kang S, Nam BH. Does neoadjuvant chemotherapy increase optimal cytoreduction rate in advanced ovarian cancer? Meta-analysis of 21 studies. Ann Surg Oncol. 2009;16:231520.

$24 \mathrm{Kim} \mathrm{JH}$, Lee JM, Ryu KS, et al. Consolidation hyperthermic intraperitoneal chemotherapy using paclitaxel in patients with epithelial ovarian cancer. J Surg Oncol. 2010;101:149-55.

${ }^{25}$ Pomel C, Ferron G, Lorimier G, et al. Hyperthermic intra-peritoneal chemotherapy using oxaliplatin as consolidation therapy for advanced epithelial ovarian carcinoma. Results of a phase II prospective multicentre trial. CHIPOVAC study. Eur J Surg Oncol. 2010;36:58993.

${ }^{26}$ Galaal K, Naik R, Bristow RE, Patel A, Bryant A, Dickinson HO. Cytoreductive surgery plus chemotherapy versus chemotherapy alone for recurrent epithelial ovarian cancer. Cochrane Database Syst Rev. 2010; 16:CD007822. Review.

${ }^{27}$ Study Comparing Tumor Debulking Surgery Versus Chemotherapy Alone in Recurrent Platinum-Sensitive Ovarian Cancer. AGO-OVAR OP.4 DESKTOP III, NCT01166737. http://www.cancer.gov/search/ResultsClinicalTrials.aspx?protocolsearchid=8354416.

${ }^{28}$ Harter P, Hahmann M, Lueck HJ, et al. Surgery for recurrent ovarian cancer: role of peritoneal carcinomatosis: exploratory analysis of the DESKTOP I Trial about risk factors, surgical implications, and prognostic value of peritoneal carcinomatosis. Ann Surg Oncol. 2009;16:1324-30.

${ }^{29}$ Hettinga JV, Lemstra W, Meijer C, et al. Mechanism of hyperthermic potentiation of cisplatin action in cisplatin-sensitive and -resistant tumour cells. $\mathrm{Br} \mathrm{J}$ Cancer. 1997;75:1735-43.

${ }^{30}$ Deraco M, Raspagliesi F, Kusamura S. Management of peritoneal surface component of ovarian cancer. Surg Oncol Clin N Am. 2003;12:561-83. Review.

${ }^{31}$ Fagotti A, Paris I, Grimolizzi F, Fanfani F, Vizzielli G, Naldini A, Scambia G. Secondary cytoreduction plus oxaliplatin-based HIPEC in platinum-sensitive recurrent ovarian cancer patients: a pilot study. Gynecol Oncol. 2009;113:335-40. 
${ }^{32}$ Helm CW, Bristow RE, Kusamura S, Baratti D, Deraco M. Hyperthermic intraperitoneal chemotherapy with and without cytoreductive surgery for epithelial ovarian cancer. J Surg Oncol. 2008;98:283-90.

${ }^{33}$ Aletti GD, Long HJ, Podratz KC, Cliby WA. Is time to chemotherapy a determinant of prognosis in advanced-stage ovarian cancer? Gynecol Oncol. 2007;104:212-6.

${ }^{34}$ Chéreau E, Ballester M, Selle F, Cortez A, Daraï E, Rouzier R. Comparison of peritoneal carcinomatosis scoring methods in predicting resectability and prognosis in advanced ovarian cancer. Am J Obstet Gynecol. 2010;202:178.e1-178.e10.

${ }^{35}$ Bartlett DL, Buell JF, Libutti SK, et al. A phase I trial of continuous hyperthermic peritoneal perfusion with tumor necrosis factor and cisplatin in the treatment of peritoneal carcinomatosis. Cancer 1998;83:1251-1261.

${ }^{36}$ Rossi CR, Foletto M, Mocellin S, et al. Hyperthermic intraoperative intraperitoneal chemotherapy with cisplatin and doxorubicin in patients who undergo cytoreductive surgery for peritoneal carcinomatosis and sarcomatosis: phase I study. Cancer. 2002; 15:94:492-9.

${ }^{37}$ Harrison LE, Bryan M, Pliner L, Saunders T. Phase I trial of pegylated liposomal doxorubicin with hyperthermic intraperitoneal chemotherapy in patients undergoing cytoreduction for advanced intra-abdominal malignancy. Ann Surg Oncol. 2008;15:140713.

38 Markman M, Brady MF, Spirtos NM, Hanjani P, Rubin SC. Phase II trial of intraperitoneal Paclitaxel in carcinoma of the ovary, tube and peritoneum: a Gynecologic Oncology Group Study. J Clin Oncol 1998;16:2620-4.

39 Nicoletto MO, Padrini R, Galeotti F, et al. Pharmacokinetics of intraperitoneal hyperthermic perfusion with mitoxantrone in EOC. Cancer Chemother Pharmacol 2000;45:457-462.

${ }^{40}$ Lentz SS, Miller BE, Kucera GL, Levine EA. Intraperitoneal hyperthermic chemotherapy using carboplatin: a phase I analysis in ovarian carcinoma. Gynecol Oncol. 2007;106:20710.

${ }^{41}$ Morgan RJ Jr, Synold TW, Xi B, et al. Phase I trial of intraperitoneal gemcitabine in the treatment of advanced malignancies primarily confined to the peritoneal cavity. Clin Cancer Res. 2007;13:1232-7. 
42 de Bree E, Rosing H, Filis D, et al. Cytoreductive surgery and intraoperative hyperthermic intraperitoneal chemotherapy with paclitaxel: a clinical and pharmacokinetic study. Ann Surg Oncol. 2008;15:1183-92.

${ }^{43}$ Smeenk RM, Verwaal VJ, Zoetmulder FA. Learning curve of combined modality treatment in peritoneal surface disease. Br J Surg. 2007;94:1408-14.

44 OVHIPEC trial; ClinicalTrials.gov identifier:

NCT00426257 http://clinicaltrials.gov/ct2/show/ NCT00426257.

${ }^{45}$ Chua TC, Liauw W, Robertson G, et al. Towards randomized trials of cytoreductive surgery using peritonectomy and hyperthermic intraperitoneal chemotherapy for ovarian cancer peritoneal carcinomatosis. Gynecol Oncol. 2009;114:137-9.

${ }^{46}$ Classe JM, Muller M, Frenel JS, Rigaud DB, Ferron G, Gladieff L. La chimiothérapie intrapéritonéale dans les cancers de l'ovaire Intra peritoneal chemotherapy in the treatment of advanced ovarian cancere-mémoires de l'Académie Nationale de Chirurgie, 2009;8:86-90.

${ }^{47}$ Bereder J, Glehen O, Habre J, et al. Cytoreductive surgery combined with perioperative intraperitoneal chemotherapy for the management of peritoneal carcinomatosis from ovarian cancer: a multiinstitutional study of 246 patients.J Clin Oncol 2009;27(15s): abstr 5542.

${ }^{48}$ Pavlov MJ, Kovacevic PA, Ceranic MS, Stamenkovic AB, Ivanovic AM, Kecmanovic DM (2009) Cytoreductive surgery and modi-Wed hyperthermic intraoperative intraperitoneal chemotherapy (HIPEC)for advanced and recurrent ovarian cancer-12-year single center experience. Eur J Surg Oncol (in press).

${ }^{49}$ Guardiola E, Delroeux D, Heyd B, et al. Intra operative intra-peritoneal chemotherapy withcisplatin in patients with peritoneal carcinomatosis of ovarian cancer. World $\mathrm{J}$ Surg Oncol 2009;9:14

${ }^{50}$ Di Giorgio A, Naticchioni E, Biacchi D, et al. Cytoreductive surgery (peritonectomy procedures) combined with hyperthermic intraperitoneal chemotherapy (HIPEC) in the treatment of diVuse peritoneal carcinomatosis from ovarian cancer. Cancer 2008;113:31525. 
51 Bae JH, Lee JM, Ryu KS, et al. Treatmentof ovarian cancer with paclitaxel- or carboplatin-based intraperitoneal hyperthermic chemotherapy during secondary surgery. Gynecol Oncol 2007;106:193-200.

${ }^{52}$ Cotte E, Glehen O, Mohamed F, et al. Cytoreductive surgery and intraperitoneal chemohyperthermia for chemo-resistant and recurrent advanced epithelial ovarian cancer: prospective study of 81 patients. World J Surg 2007;31:1813-1820.

${ }^{53}$ Rufian S, Munoz-Casares FC, Briceno J, et al. Radical surgery-peritonectomy and intraoperative intraperitoneal chemotherapy for the treatment of peritoneal carcinomatosis in recurrent or primary ovarian cancer. J Surg Oncol. 2006; 94:316-24.

${ }^{54}$ Raspagliesi F, Kusamura S, Campos Torres JC et al. Cytoreduction combined with intraperitoneal hyperthermic perfusion chemotherapy in advanced/recurrent ovarian cancer patients: the experience of National Cancer Institute of Milan. Eur J Surg Oncol 2006;32:671-75.

${ }^{55}$ Ryu KS, Kim JH, Ko HS, et al. Effects of intraperitoneal hyperthermic chemotherapy in ovarian cancer. Gynecol Oncol 2004;94:325-332. 